\title{
Serum Concentrations of Insulin, Ghrelin, Adiponectin, Leptin, Leptin Receptor and Lipocalin-2 in Children with Celiac Disease Who Do and Do Not Adhere to a Gluten-Free Diet
}

\begin{abstract}
Roman M. Janas ${ }^{1}$, Anna Rybak ${ }^{2}$, Aldona Wierzbicka-Rucińska ${ }^{1}$, Piotr Socha ${ }^{2}$, Rafał Śnitko ${ }^{1}$, Anna Szaflarska-Popławska ${ }^{3}$, Anna Stolarczyk ${ }^{2}$, Beata Oralewska ${ }^{2}$, Elżbieta Cytra-Jarocka ${ }^{4}$, Barbara Iwańczak ${ }^{5}$, Urszula Grzybowska-Chlebowczyk ${ }^{6}$, Wojciech Cichy ${ }^{7}$, Grażyna Czaja-Bulsa ${ }^{8}$, and Jerzy Socha ${ }^{2}$

Departments of ${ }^{1}$ Biochemistry, Radioimmunology and Experimental Medicine, ${ }^{2}$ Gastroenterology, Hepatology and Nutrition Disorders, The Children's Memorial Health Institute, Warsaw, ${ }^{3}$ Department of Paediatric Endoscopy and Gastrointestinal Function Testing, Nicolaus Copernicus University in Toruń, Ludwik Rydygier Collegium Medicum in Bydgoszcz, Bydgoszcz, ${ }^{4}$ Department of Pediatrics, Gastroenterology and Allergology, Medical University of Białystok, Białystok, ${ }^{5}$ Second Department of Pediatrics, Gastroenterology and Nutrition, Medical University of Wrocław, Wrocław, ${ }^{6}$ Department of Pediatrics, Division of Gastroenterology, Silesian Center for Child Health, Independent Public Clinical Hospital No. 6, Medical University of Silesia, Katowice, ${ }^{7}$ First Department of Paediatric, Department of Gastroenterology and Metabolic Diseases, Poznan University of Medical Sciences, Poznań, and ${ }^{8}$ Department of Pediatrics, Gastroenterology and Rheumatology, Pomeranian Medical University, Szczecin, Poland
\end{abstract}

Background/Aims: The roles of the many bioactive peptides in the pathogenesis of celiac disease remain unclear. To evaluate the serum concentrations of insulin, ghrelin, adiponectin, leptin, leptin receptor, and lipocalin-2 in children with celiac disease who do and do not adhere to a gluten-free diet (GFD, intermittent adherence). Methods: Prepubertal, pubertal, and adolescent celiac children were included in this study ( 74 girls and 53 boys on a GFD and 80 girls and 40 boys off of a GFD). Results: Insulin levels in prepubertal $(9.01 \pm 4.43 \mu \mathrm{lU} / \mathrm{mL})$, pubertal $(10.3 \pm 3.62 \mu \mathrm{lU} / \mathrm{mL})$, and adolescent $(10.8 \pm 4.73 \mu \mathrm{lU} / \mathrm{mL})$ girls were higher than those in boys $(5.88 \pm 2.02,8.81 \pm 2.88$, and $8.81 \pm 2.26 \mu \mathrm{IU} / \mathrm{mL}$, respectively) and were neither age-dependent nor influenced by a GFD. Prepubertal children off of a GFD exhibited higher ghrelin levels than prepubertal children on a GFD. Adiponectin levels were not age-, sex- nor GFD-dependent. Adherence to a GFD had no effect on the expression of leptin, leptin receptor, and lipocalin-2. Conclusions: Adherence to a GFD had no influence on the adiponectin, leptin, leptin receptor, and lipocalin-2 concentrations in celiac children, but a GFD decreased highly elevated ghrelin levels in prepubertal children. Further studies are required to determine whether increased insulin concentrations in girls with celiac disease is suggestive of an increased risk for hyperinsulinemia. (Gut Liver 2016;10:587-594)
Key Words: Insulin; Ghrelin; Lipocalin-2; Diet, gluten-free; Celiac disease

\section{INTRODUCTION}

In genetically susceptible humans ingestion of gluten may precipitate celiac disease (CD). This autoimmune and inflammatory disease affects about 1\% people (65\% women, 35\% men) at any age. Its main manifestations include diarrhea, abdominal distension and in children, failure to thrive, chronic or recurrent intestinal inflammation, malnutrition, and also vomiting, anemia, disturbances in energy metabolism. CD is diagnosed based on the clinical evaluation, and serologic determinations (autoantibodies of the IgA and/or IgG class against tissue transglutaminase [tTG], endomysium, and deamidated gliadin peptides [DGP]). Finally, diagnosis of CD may be proven by the histological evaluation. ${ }^{1,2}$

In children, clinical presentations of $\mathrm{CD}$ depend on the age and subtype of the disease (classic, atypical, or silent CD). Infants and younger children manifest classical triad of the $\mathrm{CD}$ symptoms whereas in older children extraintestinal signs are often seen (short stature, neuropsychiatric disturbances, osteopenia, and anemia).,4 Although the body mass index (BMI) of majority of $\mathrm{CD}$ children remains still lower as compared to the

\footnotetext{
Correspondence to: Roman M. Janas

Department of Biochemistry, Radioimmunology and Experimental Medicine, The Children's Memorial Health Institute, Al. Dzieci Polskich 20, 04736 Warsaw, Poland

Tel: +48-22-815-73-04, Fax: +48-22-815-13-13, E-mail: r.janas@czd.pl

Received on August 19, 2015. Revised on September 24, 2015. Accepted on October 12, 2015. Published online April 20, 2016 pISSN 1976-2283 eISSN 2005-1212 http://dx.doi.org/10.5009/gnl15404

@ This is an Open Access article distributed under the terms of the Creative Commons Attribution Non-Commercial License (http://creativecommons.org/licenses/by-nc/4.0) which permits unrestricted non-commercial use, distribution, and reproduction in any medium, provided the original work is properly cited.
} 
healthy children, there is an increasing number of overweight patients. $^{5-7}$

Gluten proteins (gliadins and glutenins) are resistant to complete hydrolysis by gastrointestinal proteases. Products of their partial hydrolysis also remain resistant for further degradation. ${ }^{1,8}$ They accumulate in the intestinal lumen (and in circulation) and may cross the epithelial barrier, react with the antigenpresenting cells and initiate innate inflammatory process. tTG deamidates gliadins what enhances their immunogenicity and capability of binding to HLA-DQ2 expressed on the presenting cells that cause generation of specific CD4 lymphocytes. The cells secrete proinflammatory cytokines, activate autoreactive B lymphocytes and produce antibodies to the complex tTGdeamidated gluten. ${ }^{1-3}$ Further, tTG enhances inflammation via downregulation of peroxisome proliferator-activated receptor- $\gamma$ (PPAR- $\gamma)$. Mesenteric white adipose tissue that surrounds diseased intestine may be an additional source of pro- and antiinflammatory substances. ${ }^{9}$

In about 75\% of CD patients gluten-free diet (GFD) causes significant or complete renewal of the damaged intestinal mucosa. ${ }^{1,2}$ In children with CD-related growth retardation, GFD causes significant catch-up growth. ${ }^{10}$ Rapid recurrence of the symptoms takes place when strict adherence to a GFD is discontinued. In numerous CD patients on a GFD massive intraepithelial lymphocytosis persists for the long time. Also, some patients may exhibit increased resting metabolism rate.,11 However, $10 \%$ to $19 \%$ of patients do not response to a GFD and represent nonresponsive type of CD ( $\mathrm{rCD}$ ). Low compliance with a GFD or low quality, gluten-contaminated food seems to be a major cause of $n r C D$. About $4 \%$ of the CD patients on a strict GFD with no other intestinal diseases exhibit nrCD symptoms that are due to the refractory type of CD. Elevated levels of the antiDGP IgG-class antibodies in CD patients on a strict GFD are helpful in the identification of the $\operatorname{nrCD}$ patients. ${ }^{1,3,12}$

In contrast to other inflammatory gut diseases, the role of adipokines and metabolism regulating factors is not completely recognized in pathophysiology, course and treatment of $\mathrm{CD}$. $\mathrm{CD}$ patients may be at risk of metabolic syndrome where adipokines and other bioactive peptides play an important role. Moreover, GFD is not neutral and seems to cause disturbances in the homeostasis of micronutrients and various bioactive substances. Therefore, one of the aims of present, multicenter, cross-sectional study was to evaluate the serum concentrations of insulin, ghrelin, adiponectin, leptin and its soluble receptor, and lipocalin-2 in prepubertal, pubertal, and adolescent CD with and without adherence to a GFD.

\section{MATERIALS AND METHODS}

Protocol of this cross-sectional, multicenter study was approved by the local bioethics committee. Written consents were obtained from the patients.

\section{Patients}

Group of 248 children suffering CD from 1 to 6 years (mean, 3 years), girls $(n=154)$ and boys $(n=94)$, aged from 1 to 18 years (mean, 7 years) was included in the study. Diagnosis was based on the clinical evaluation, celiac serology, and histological examination according to the guidelines of North America Society for Pediatric Gastroenterology, Hepatology and Nutrition and/ or European Society for Pediatric Gastroenterology, Hepatology and Nutrition (ESPGHAN). ${ }^{3,4}$

Exclusion criteria were CD children with other inflammatory and autoimmune diseases including type 1 diabetes mellitus, growth hormone deficiency, endocrinological and genetic disorders.

At the time of diagnosis, about $69 \%$ of the CD children presented classical form of the disease, whereas 30\% had atypical and 1\% silent form of the $\mathrm{CD}$, and 62\% had normal z-score BMI, 31\% was underweight and 7\% was overweight. About $98 \%$ of the children exhibited presence of antiendomysium and anti-tTG antibodies, and in 7\% IgA deficiency was found. Villous atrophy at grade III on the Oberrhuber-Marsh classification was present in $98 \%$ children. ${ }^{13}$

The CD children and/or their parents were educated how to prepare and follow a balanced GFD in which almost 60\% of energy should originate from carbohydrates, 10\% to 15\% from protein and 25\% to 30\% from fat intake according to the ESPGHAN recommendations. The GFD was not fortified nor supplemented.

The study group was subdivided into two main subgroups: (1) children following a GFD (on a GFD), n=127 (74 girls and 53 boys), and (2) children not following a GFD (off a GFD), $n=120$ (80 girls and 40 boys) in which tTG was $>8 \mathrm{IU} / \mathrm{mL}$ or, in the IgA deficient children, DGP was $>25 \mathrm{IU} / \mathrm{mL}$. Children were on a GFD for at least 1 year. The patients were further divided due to their gender and pubertal stage as shown on the Table 1.

\section{Assays}

Blood was sampled after overnight fasting and the sera were obtained applying Good Laboratory Practice procedures. The assays were performed in one laboratory using commercial kits.

Human Insulin IRMA kit (sensitivity, $1 \mu \mathrm{IU} / \mathrm{mL}$; intra- and interassay coefficient of variation [CV], 2.1\% and 6.5\%) was from DIAsource ImmunoAssays, Louvain-la-Neuve, Belgium. Total Ghrelin ELISA kit (sensitivity, 100 pg/mL; inter- and intra-assay CV, 1.9\% and 7.8\%) and Leptin (Sandwich) ELISA (sensitivity, 1.0 $\mathrm{ng} / \mathrm{mL}$; intra- and interassay CV, 6.9\% and 11.5\%) were from DRG International Inc., Springfield, NJ, USA.

Human Adiponectin RIA kit (sensitivity, $1 \mathrm{ng} / \mathrm{mL}$; intraand interassay CV was 6.2\% and 9.3\%) was from Millipore, St. Louis, MO, USA. Human Leptin Soluble Receptor ELISA kit (sensitivity, $0.04 \mathrm{ng} / \mathrm{mL}$; intra- and interassay CV, 7.2\% and 9.8\%) and lipocalin-2 (neutrophil gelatinase-associated lipocalin; sen- 
Table 1. The Study Subgroups of Children with Celiac Disease

\begin{tabular}{cclccc}
\hline Gender & On/off GFD & Variable & Prepubertal & Pubertal & Adolescent \\
\hline \multirow{2}{*}{ Girls } & On GFD & Age, $\mathrm{yr}$ & $5.9 \pm 2.2(24)$ & $11.8 \pm 1.4(23)$ & $15.9 \pm 1.2(27)$ \\
& & BMI, kg/m $/ \mathrm{m}^{2}$ & $-0.36 \pm 1.23$ & $-0.75 \pm 0.98$ & $-1.18 \pm 2.22$ \\
& \multirow{2}{*}{ Off GFD } & Age, $\mathrm{yr}$ & $4.2 \pm 2.5(28)$ & $11.6 \pm 1.2(33)$ & $16.2 \pm 1.3(19)$ \\
& & BMI, $\mathrm{kg} / \mathrm{m}^{2}$ & $-0.55 \pm 0.89$ & $-0.37 \pm 1.10$ & $-0.37 \pm 1.31$ \\
Boys & On GFD & Age, $\mathrm{yr}$ & $6.1 \pm 1.7(16)$ & $12.3 \pm 0.8(18)$ & $15.6 \pm 1.0(19)$ \\
& & BMI, $\mathrm{kg} / \mathrm{m}^{2}$ & $-0.41 \pm 0.96$ & $-0.75 \pm 0.98$ & $-0.61 \pm 0.88$ \\
& Off GFD & Age, $\mathrm{yr}$ & $4.8 \pm 2.2(17)$ & $11.9 \pm 0.9(14)$ & $16.2 \pm 1.3(10)$ \\
& & BMI, $\mathrm{kg} / \mathrm{m}^{2}$ & $-0.21 \pm 1.14$ & $0.09 \pm 0.82$ & $0.32 \pm 0.65$ \\
\hline
\end{tabular}

Data are presented as mean \pm SD (n) or mean \pm SD.

GFD, gluten-free diet; BMI, body mass index.

Table 2. Serum Lipocalin-2 (Neutrophil Gelatinase-Associated Lipocalin) in Children with Celiac Disease Either on or off of a Gluten-Free Diet

\begin{tabular}{|c|c|c|c|c|c|c|c|}
\hline & \multicolumn{3}{|c|}{$\begin{array}{l}\text { On GFD (age, } 14.3 \pm 2.1 \text { yr) } \\
\qquad(\mathrm{n}=22)\end{array}$} & \multicolumn{3}{|c|}{$\begin{array}{l}\text { Off GFD (age, } 14.8 \pm 1.4 \mathrm{yr}) \\
\qquad(\mathrm{n}=15)\end{array}$} & \multirow{2}{*}{$\mathrm{p}$-value } \\
\hline & Median & Q1/Q3 (range) & $\mathrm{Mean}_{ \pm} \mathrm{SD}$ & Median & Q1/Q3 (range) & $\mathrm{Mean}_{ \pm} \mathrm{SD}$ & \\
\hline Lipocalin-2, ng/mL & 39.7 & $30.6 / 48.6(23.9-79.1)$ & $41.9 \pm 13.5$ & 45.8 & 39.4/63.9 (30.6-83.6) & $51.4 \pm 17.5$ & NS \\
\hline
\end{tabular}

GFD, gluten-free diet; Q1/Q3, 25th and 75th percentiles; NS, not significant.

sitivity, $0.02 \mathrm{ng} / \mathrm{mL}$; intra- and interassay CV, 8.4\% and 9.8\%) were from Biovendor-Laboratorni Medicina a.s., Brno, Czech Republic.

Due to limited volume of the sera, serum lipocalin-2 was measured in the group of older children: in those on a GFD, girls and boys aged $14.3 \pm 2.1$ years $(n=22)$ and in those off a GFD, girls and boys aged 14.8 \pm 1.4 years $(n=15)$.

\section{Statistical analysis}

The Statistica version 7.0 software (StatSoft Inc., Tulsa, OK, USA) was used for data analysis. Results in the Figs 1-5 are expressed as median, quartile 1st and 3rd, and range. In the text and in the Table 2, the data are expressed also as mean \pm SD. The mean \pm SD values are presented in the following order: analyte, unit, group: prepubertal, pubertal, and adolescent girls on a GFD versus off a GFD and boys on a GFD versus off a GFD. The analyzed groups were not numerous and had non-normal distribution, according to Shapiro-Wilk test for normality, therefore the associations between groups were assessed using Mann-Whitney U test with p-value less than 0.05 was considered significant.

\section{RESULTS}

\section{Insulin ( $\mu \mathrm{IU} / \mathrm{mL})$}

Insulin levels were as follows; prepubertal girls: $9.01 \pm 4.43$ vs $7.44 \pm 3.84$ ( $p>0.05$ ) and boys: $5.88 \pm 2.02$ vs $5.06 \pm 1.57$ ( $>>0.05$ ), pubertal girls: $10.3 \pm 3.62$ vs $9.61 \pm 4.32$ ( $p>0.05$ ) and boys: $8.81 \pm 2.88$ vs $6.49 \pm 2.78$ ( $>>0.05$ ), adolescent girls: $10.8 \pm 4.73$ vs $11.3 \pm 6.19$ (p>0.05) and boys: $8.81 \pm 2.26$ vs $7.53 \pm 3.10 \mu \mathrm{IU} / \mathrm{mL}$

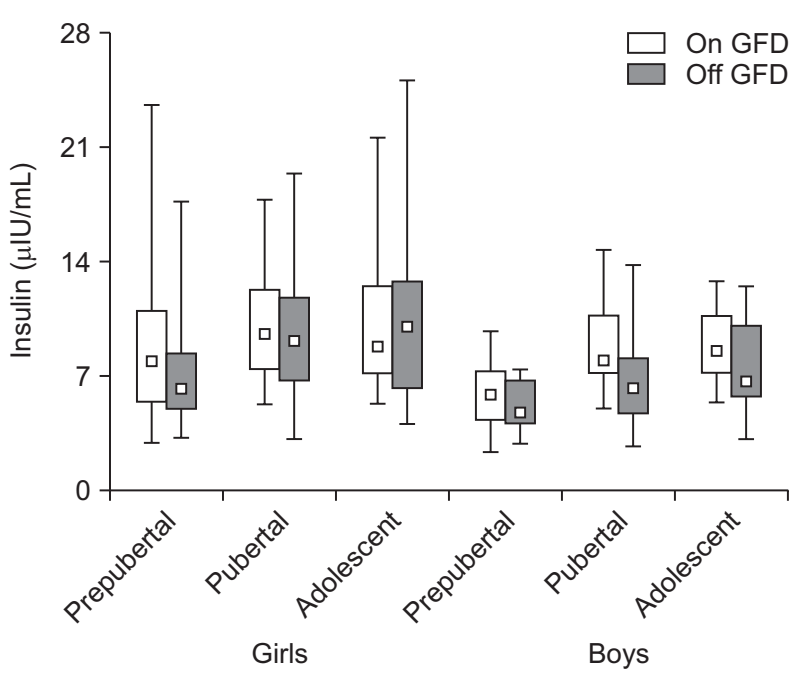

Fig. 1. A gluten-free diet (GFD) did not affect the serum insulin concentration in prepubertal, pubertal, and adolescent girls and boys with celiac disease ( $>00.05)$. Serum insulin concentrations were sexdependent $(p<0.05)$ but not age-dependent $(p>0.05)$. The data consist of the median, Q1-Q3 (quartiles 1-3), and range.

( $>0.05$ ) (Fig. 1). Insulin levels in prepubertal, pubertal, and adolescent girls and boys on a GFD were not significantly different from those in corresponding groups of girls and boys being off a GFD ( $p>0.05)$. The mean levels were gender- $(p<0.05)$ but not age-dependent $(p>0.05)$, significantly higher in girls than in boys $(\mathrm{p}<0.05)$, and remained within the insulin normal range: 3 to $15 \mu \mathrm{IU} / \mathrm{mL}$. 


\section{Total ghrelin $(\mathrm{pg} / \mathrm{mL})$}

Total ghrelin levels were as follows; prepubertal girls: $579 \pm 151$ vs $772 \pm 344(p<0.05)$ and boys: $378 \pm 172$ vs $865 \pm 415(p<0.05)$, pubertal girls: $385 \pm 249$ vs $412 \pm 205$ ( $>>0.05$ ) and boys: $495 \pm 299$ vs $478 \pm 293$ ( $p>0.05$ ), adolescent girls: $395 \pm 220$ vs $401 \pm 139$ ( $>0.05$ ) and boys: $412 \pm 160$ vs $423 \pm 152 \mathrm{pg} / \mathrm{mL}$ (p>0.05) (Fig. 2). Total ghrelin levels were significantly higher in prepubertal girls and boys being off a GFD ( $\mathrm{p}<0.05)$. Decrease of the ghrelin levels in prepubertal boys on a GFD was significantly dipper than in the corresponding group of girls $(p<0.05)$. In the older chil-

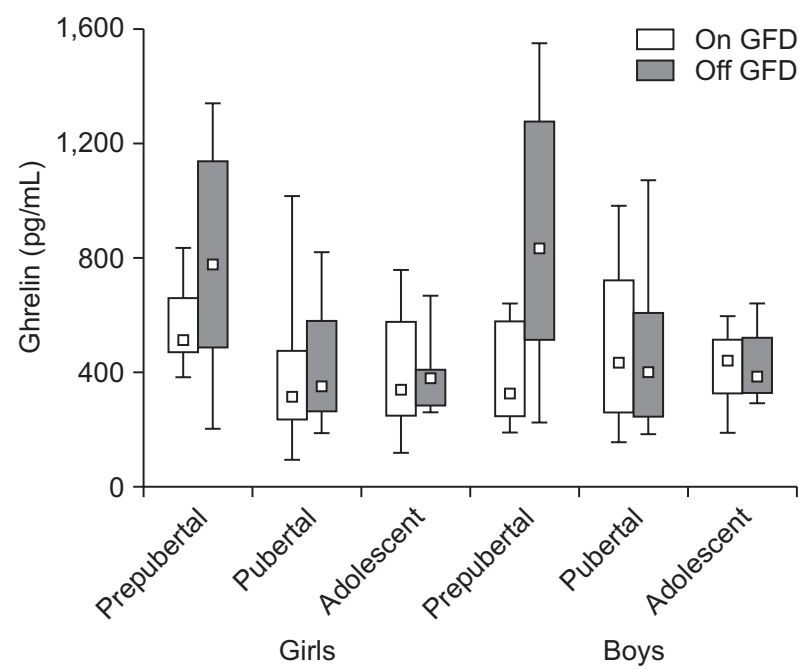

Fig. 2. A gluten-free diet (GFD) significantly decreased the total serum ghrelin concentration in prepubertal girls and boys $(\mathrm{p}<0.05)$ but did not have a significant effect in older children $(p>0.05)$. The data consist of the median, Q1-Q3 (quartiles 1-3), and range.

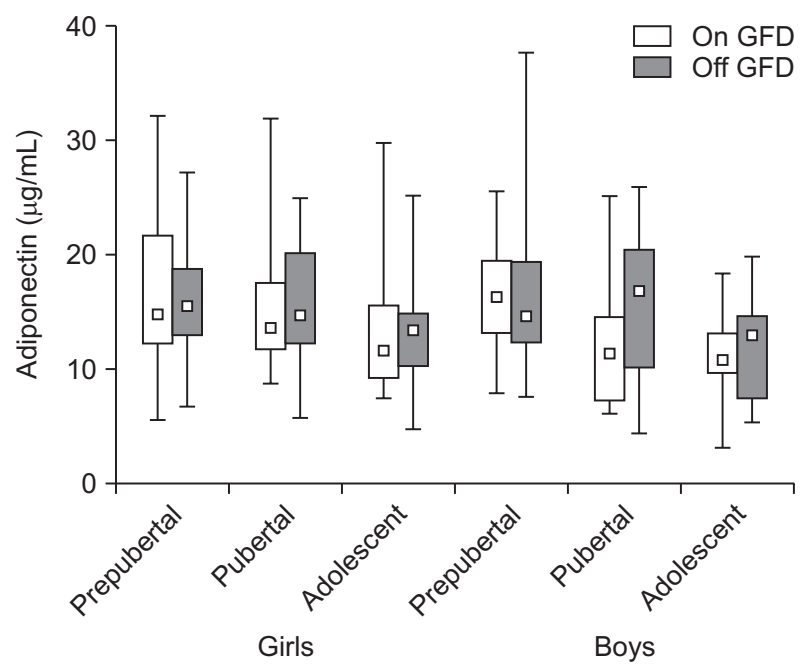

Fig. 3. A gluten-free diet (GFD) did not affect the serum adiponectin concentrations in prepubertal, pubertal, and adolescent girls and boys with celiac disease $(p>0.05)$, and the concentrations were not ageand sex-dependent $(p>0.05)$. The data are expressed as the median, Q1-Q3 (quartiles 1-3), and range. dren on and off a GFD the ghrelin levels were not significantly different ( $p>0.05)$.

\section{Adiponectin $(\mu \mathrm{g} / \mathrm{mL})$}

Adiponectin levels were as follows; prepubertal girls: $16.9 \pm 6.00$ vs $16.3 \pm 5.20$ ( $p>0.05$ ) and boys: $16.3 \pm 4.74$ vs $17.2 \pm 7.76$ ( $p>0.05$ ), pubertal girls: $15.8 \pm 5.78$ vs $15.3 \pm 5.43$ ( $p>0.05$ ) and boys: $12.9 \pm 5.19$ vs $16.0 \pm 6.18$ ( $p>0.05$ ), adolescent girls: $13.4 \pm 5.50$ vs $13.6 \pm 4.50$ ( $>>0.05$ ) and boys: $10.9 \pm 3.65$ vs $12.5 \pm 5.28 \mu \mathrm{g} / \mathrm{mL}$ ( $>>0.05$ ) (Fig. 3). Adiponectin levels were the same in children on and off a GFD and were not sex- and age-dependent ( $p>0.05)$.

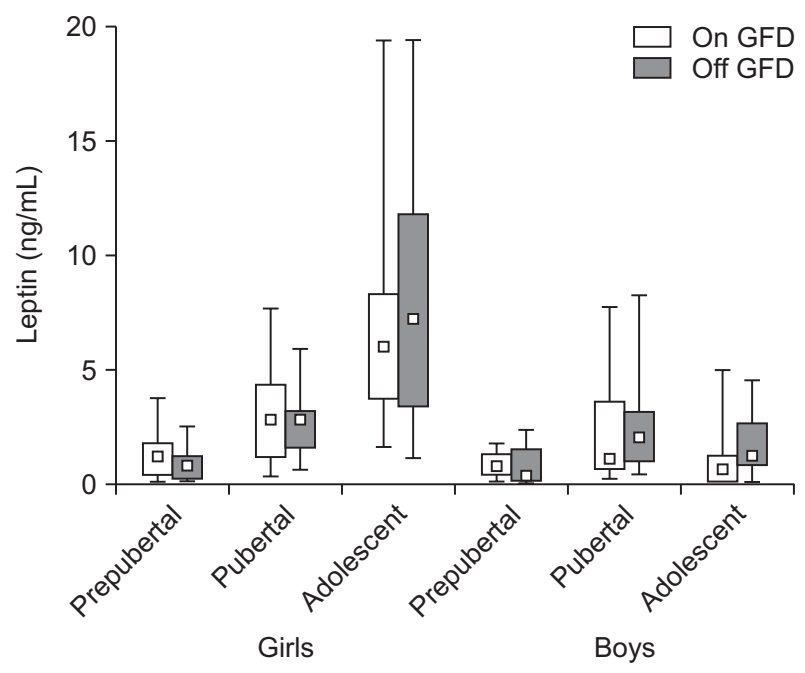

Fig. 4. A gluten-free diet (GFD) did not influence the serum leptin level in prepubertal, pubertal and, adolescent girls and boys with celiac disease $(p>0.05)$. The leptin concentrations were age- and sexdependent $(\mathrm{p}<0.05)$. The data are expressed as the median, Q1-Q3 (quartiles 1-3), and range.

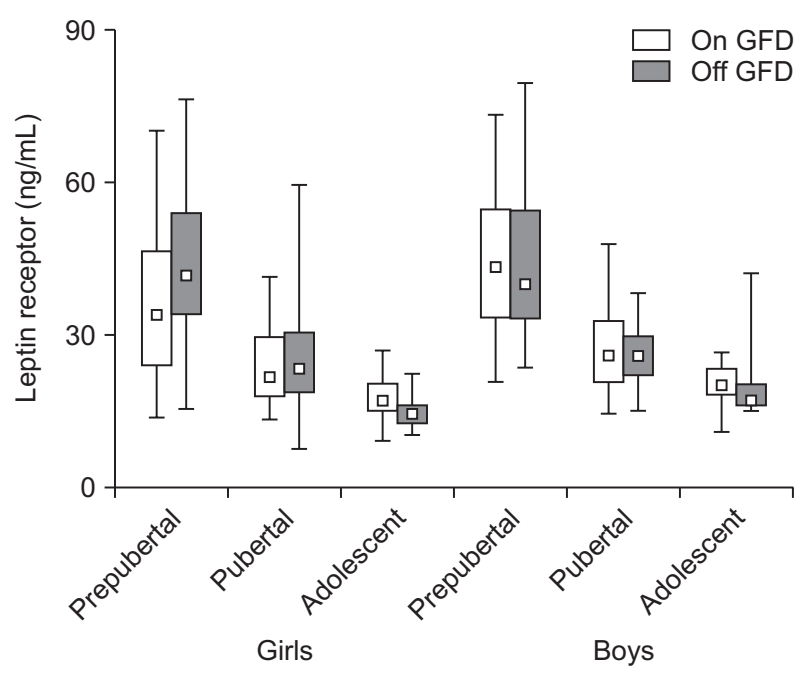

Fig. 5. A gluten-free diet (GFD) did not affect the serum levels of the soluble leptin receptor in prepubertal, pubertal and adolescent girls and boys with celiac disease ( $>0.05)$. The leptin receptor levels were age-dependent but not sex-dependent $(\mathrm{p}<0.05)$. The data are expressed as the median, Q1-Q3 (quartiles 1-3), and range. 


\section{Leptin (ng/mL)}

Leptin levels were as follows; prepubertal girls: $1.31 \pm 1.01$ vs $0.88 \pm 0.71$ ( $p>0.05$ ) and boys: $0.81 \pm 0.52$ vs $0.73 \pm 0.86$ ( $>>0.05)$, pubertal girls: $3.05 \pm 2.16$ vs $2.65 \pm 1.29$ ( $p>0.05$ ) and boys: $1.96 \pm 2.06$ vs $2.63 \pm 2.43$ ( $>0.05$ ), adolescent girls: $6.70 \pm 3.93$ vs $8.12 \pm 5.79$ ( $>>0.05$ ) and boys: $0.90 \pm 1.12$ vs $1.75 \pm 1.42 \mathrm{ng} / \mathrm{mL}$ ( $p>0.05$ ) (Fig. 4). Leptin levels were not affected by a GFD both in girls and boys ( $>>0.05)$, but were sex- and age-dependent $(\mathrm{p}<0.05)$

\section{Leptin receptor $(\mathrm{ng} / \mathrm{mL})$}

Leptin receptor levels were as follows; prepubertal girls: $36.8 \pm 15.7$ vs $43.6 \pm 13.7$ ( $p>0.05$ ) and boys: $44.8 \pm 14.4$ vs $43.8 \pm 15.4$ ( $p>0.05$ ), pubertal girls: $24.5 \pm 8.14$ vs $24.9 \pm 10.1$ ( $p>0.05$ ) and boys: $27.7 \pm 8.81$ vs $25.6 \pm 6.50$ ( $>>0.05$ ), adolescent girls: $17.2 \pm 4.63$ vs $14.9 \pm 3.21$ ( $p>0.05$ ) and boys: $20.8 \pm 3.88$ vs $21.5 \pm 9.00 \mathrm{ng} / \mathrm{mL}$ (p>0.05) (Fig. 5). Leptin soluble receptor levels were not affected by a GFD in prepubertal, pubertal and adolescence girls and boys $(p>0.05)$, and were age- $(p<0.05)$ but not sex-dependent ( $p>0.05)$.

\section{Lipocalin-2 (ng/mL)}

Lipocalin-2 levels in children following on or off of a GFD were $41.9 \pm 13.5$ and $51.4 \pm 17.5$ (Table 2). The levels were not significantly different between children on and off a GFD and the lipocalin-2 normal range that we have worked out: median, 57.6; range, 28.7 to 107 ; mean, $61.5 \pm 21.5 \mathrm{ng} / \mathrm{mL}$ ( $>>0.05$ ).

\section{DISCUSSION}

We have investigated the serum levels of insulin, total ghrelin adiponectin, leptin and its soluble receptor and lipocalin-2 in prepubertal, pubertal and adolescent CD girls and boys with and without adherence to a GFD.

We have shown that prepubertal, pubertal and adolescent CD girls exhibit significantly higher insulin concentrations than prepubertal, pubertal and adolescent boys. There was no significant effect of a GFD on the insulin levels in CD girls and boys. Our data suggest that $\mathrm{CD}$ girls seem to exhibit tendency to hyperinsulinemia in contrast to $\mathrm{CD}$ boys where the insulin concentrations are tightly regulated (Fig. 1). Recently, important paper has been published showing that CD adults are protected from the type 2 diabetes and metabolic syndrome. ${ }^{14}$ This specific protective effect of the disease was not associated with the differences in BMI in the patients. Mechanism of this intriguing finding may include altered pancreatic and mucosal endocrine functions. ${ }^{14}$ In contrast, in the most recent paper, the authors report that $\mathrm{CD}$ adults are at high risk of metabolic syndrome and hepatic steatosis in result of 1-year treatment with a GFD. ${ }^{15}$ The authors suggest that specific disturbances in glucose homeostasis may lead to hyperinsulinemia. Also, upregula- tion of PPAR- $\gamma$ due to a GFD has been shown to be implicated in susceptibility of type 2 diabetes. ${ }^{15}$ Interestingly, there is a need to consider recent data on glucose/insulin homeostasis in patients with inflammatory bowel disease (IBD). ${ }^{16}$ The authors report significant hyperinsulinemia with no changes in glucose concentrations in their patients. Moreover, hyperinsulinemia appears as an independent protective factor for the maintenance of IBD remission. ${ }^{16}$ Similar data were also reported in the earlier study for the patients with Crohn's disease. ${ }^{17}$ Insulin is a potent protein-anabolic and anti-inflammatory peptide. These actions are beneficial in the intestine inflammatory conditions. Our and cited data suggest an involvement of the insulin and glucose homeostasis in pathogenesis of $\mathrm{CD}$. This topic requires systematic studies.

Our prepubertal girls and boys being off a GFD exhibited significant elevation of their serum total ghrelin levels as compared to the levels in prepubertal children on a GFD as well as to those in pubertal and adolescent girls and boys on and off a GFD (Fig. 2). Decrease of the ghrelin level in result of a GFD adherence in prepubertal boys was significantly deeper than in prepubertal girls. There was no significant difference in ghrelin between pubertal and adolescent girls and boys and no influence of a GFD on it. Results from other studies are confusing. ${ }^{18-23}$ Some authors have shown significant increase of the ghrelin levels in untreated CD patients that returned to normal during a GFD. ${ }^{18}$ Other authors reported the same ghrelin concentrations in untreated $\mathrm{CD}$ adults and in controls that significantly decreased during a GFD. ${ }^{19}$ Other yet authors have shown ghrelin levels in untreated $\mathrm{CD}$ adults 5 -fold higher than those in controls. ${ }^{22}$ It has been also reported that serum ghrelin in untreated CD boys and girls was significantly lower after a GFD. ${ }^{23}$ Reasons for these discrepancies remain unclear. In contrast, results on the circulating ghrelin in IBD patients are consistent. Both, total and acylated ghrelin levels were shown to be significantly elevated and decreased in result of treatment. ${ }^{24-26}$ Orexigenic ghrelin stimulates growth hormone (GH) release, appetite, adipogenesis, gut motility and inhibits expression of proinflammatory cytokines. Administration of ghrelin to humans with various diseases resulted in retention of lean body mass and decrease of circulating proinflammatory cytokines; all the actions are beneficial for CD patients. ${ }^{27,28}$ Nutritional status, but not mucosal inflammation, seems to be a main factor regulating ghrelin secretion specially in younger children.

In our study serum adiponectin levels were not age- and gender-related and remained unaffected by a GFD adherence (Fig. 3). It has been recently shown that adiponectin levels in $\mathrm{CD}$ adults were significantly increased, and like in our study, remained unchanged after a GFD. The authors suggest that, in contrast to IBD, adiponectin may act as proinflammatory adipokine in specific CD conditions. ${ }^{29}$ Adiponectin is an anti-inflammatory substance. It antagonize actions of tumor necrosis factor $\alpha$, secretion of interleukin-6, and induces production of inter- 
leukin-10, interleukin-1R and interferon $\gamma$. It forms complex homopolymers which biological action(s) and their impact on various assays is unknown. ${ }^{27,30,31}$ In IBD patients serum levels of adiponectin were found to be the same like in healthy subjects, elevated or decreased. They did or did not correlate with the IBD activity indices and were or were not changed after antiinflammatory therapy. ${ }^{32-36}$ Due to contradictory results, studies on adiponectin in intestinal inflammatory conditions have to be continued.

Our data suggest that there is no influence of a GFD on the leptin and leptin soluble receptor levels in prepubertal, pubertal and adolescent CD children. Due to onset of puberty, our CD girls exhibited increase of their leptin and parallel decrease of the leptin soluble receptor. Our results agreed with the data obtained for healthy children. ${ }^{37,38}$ In pubertal boys the fold of leptin increase was significantly lower than in the girls and, in contrast to girls, it significantly decreased in adolescence. Leptin soluble receptor levels were slightly higher in boys than in girls, (Figs 4 and 5). It has been recently shown that serum leptin concentrations were the same in adult CD patients being on or off a GFD and in healthy adults. ${ }^{29}$ Other authors have demonstrated that prepubertal CD girls and boys exhibited significant lowering of the serum leptin which significantly increased after 1-year of a GFD and positively correlated with BMI. ${ }^{39}$ Similar results were reported for the $\mathrm{CD}$ children and adults although in these patients there was no increase of the leptin level after a GFD despite significant increase in fat mass. ${ }^{40}$ In IBD patients, serum leptin levels were found to be decreased (with or without statistical significance) and did not correlate with the indices of disease activity. However, some authors have found increased levels of the serum leptin that positively correlated with IBD. ${ }^{25,35,41}$ Reasons for these discrepancies are unclear. Leptin has strong proinflammatory activity. However, it also may exhibit potent anti-inflammatory properties via stimulation of interleukin-1Ra synthesis. Leptin deficiency may cause impaired T-cell proliferation and increased mortality in children due to infections. ${ }^{25,27,31}$ Leptin system consists from the free leptin (about $10 \%$ ), receptor bound fraction and a pool of the tissue and soluble leptin receptor. Free leptin strictly reflects body fat mass and correlates with the degree of insulin resistance. Proinflammatory actions seems to be associated with the receptor bound fraction of leptin. It seems that parallel measurement of the leptin receptor, bound and free leptin fraction may be important for the future CD studies. Evaluation of the leptin system may be complicated since gluten is present in the circulation (in CD and healthy subjects) at high concentrations (40 to $50 \mathrm{ng} / \mathrm{mL}$ ) and may disturb binding of leptin to its receptors. However, in CD patients the anti-gluten antibodies may ameliorate these interactions. ${ }^{37,38,42,43}$ This intriguing problem requires further studies.

Lipocalin-2 (neutrophil gelatinase-associated lipocalin), an acute phase glycoprotein, is present in tissues, blood plasma and, as an excrete, in urine and feces. It is secreted by neutro- phils, macrophages, intestinal epithelial cells and other cells. Lipocalin-2 secretion is increased in acute and chronic diseases in response to cellular injury and inflammation. It plays a crucial role in turnover of the ferric ions and in hypoferremia related bacteriostasis. ${ }^{44}$ It appears to be a valuable marker to monitor intestinal inflammation in IBD adults and children. In some IBD patients its highly increased serum concentrations correlate with the indices of the disease activity. ${ }^{45,46}$ In contrast, there is little data on a role of lipocalin-2 in pathogenesis of CD children and adults. Our results suggest that there is no involvement of the circulating lipocalin-2 in CD in children, and there is no effect of a GFD on the protein level. Moreover, lipocalin-2 levels were not significantly different from those in apparently healthy children. ${ }^{45}$ Therefore, in contrast to IBD patients, inflammatory pathways in CD seem not to be lipocalin-2 dependent. It remains to determine whether lipocalin-2 concentrations are increased in the feces of $\mathrm{CD}$ patients.

In summary, despite of limitations of our study like as lack of sex- and age-matched control groups, its cross-sectional character, small subgroups of the CD children, several findings have been obtained. Our CD girls, but not boys, exhibited elevated concentrations of their fasting insulin. The elevation was not age- and a GFD-dependent. Further studies are required to confirm whether $\mathrm{CD}$ girls exhibit increased risk for hyperinsulinemia. In prepubertal CD girls and boys being off a GFD serum concentrations of ghrelin were significantly elevated as compared to those in prepubertal CD girls and boys on a GFD. Ghrelin levels in pubertal and adolescent CD girls and boys were not significantly different and not influenced by a GFD.

Serum adiponectin concentrations were not age- and sexdependent in our CD children and were not affected by a GFD. Serum leptin levels were both sex- and age dependent and not affected by a GFD whereas leptin soluble receptor exhibited significant age- but not sex- dependence and it was not affected by a GFD. It seems unlikely that adiponectin, leptin and its receptor may play a direct role in pathogenesis of $\mathrm{CD}$ although local changes of their concentrations in the inflamed intestine are not excluded. There was no CD children with the increased level of lipocalin-2 and no influence of a GFD adherence on it.

\section{CONFLICTS OF INTEREST}

No potential conflict of interest relevant to this article was reported.

\section{ACKNOWLEDGEMENTS}

This project was supported by grant entitled "Atherosclerotic risk factors in children with celiac disease" (grant from Polish Ministry of Science and Higher Education 1171/B/P01/2010/39 to J.S.). We thank Nestle Poland for their financial support in publishing our manuscript. 


\section{REFERENCES}

1. Green PH, Cellier C. Celiac disease. N Engl J Med 2007;357:17311743.

2. Guandalini S, Assiri A. Celiac disease: a review. JAMA Pediatr 2014;168:272-278.

3. Hill ID, Dirks MH, Liptak GS, et al. Guideline for the diagnosis and treatment of celiac disease in children: recommendations of the North American Society for Pediatric Gastroenterology, Hepatology and Nutrition. J Pediatr Gastroenterol Nutr 2005;40:1-19.

4. Husby S, Koletzko S, Korponay-Szabó IR, et al. European Society for Pediatric Gastroenterology, Hepatology, and Nutrition guidelines for the diagnosis of coeliac disease. J Pediatr Gastroenterol Nutr 2012;54:136-160.

5. McGowan KE, Castiglione DA, Butzner JD. The changing face of childhood celiac disease in North America: impact of serological testing. Pediatrics 2009;124:1572-1578.

6. Brambilla P, Picca M, Dilillo D, et al. Changes of body mass index in celiac children on a gluten-free diet. Nutr Metab Cardiovasc Dis 2013;23:177-182.

7. Tucker E, Rostami K, Prabhakaran S, Al Dulaimi D. Patients with coeliac disease are increasingly overweight or obese on presentation. J Gastrointestin Liver Dis 2012;21:11-15.

8. Wieser H, Koehler P. The biochemical basis of celiac disease. Cereal Chem 2008;85:1-13.

9. Garrote JA, Gómez-González E, Bernardo D, Arranz E, Chirdo F. Celiac disease pathogenesis: the proinflammatory cytokine network. J Pediatr Gastroenterol Nutr 2008;47 Suppl 1:S27-S32.

10. Boguszewski MC, Cardoso-Demartini A, Geiger Frey MC, Celli A. Celiac disease, short stature and growth hormone deficiency. Transl Gastrointest Cancer 2015;4:69-75.

11. Gujral N, Freeman HJ, Thomson AB. Celiac disease: prevalence, diagnosis, pathogenesis and treatment. World J Gastroenterol 2012;18:6036-6059.

12. Spatola BN, Kaukinen K, Collin P, Mäki M, Kagnoff MF, Daugherty PS. Persistence of elevated deamidated gliadin peptide antibodies on a gluten-free diet indicates nonresponsive coeliac disease. Aliment Pharmacol Ther 2014;39:407-417.

13. Oberhuber G, Granditsch G, Vogelsang H. The histopathology of coeliac disease: time for a standardized report scheme for pathologists. Eur J Gastroenterol Hepatol 1999;11:1185-1194.

14. Kabbani TA, Kelly CP, Betensky RA, et al. Patients with celiac disease have a lower prevalence of non-insulin-dependent diabetes mellitus and metabolic syndrome. Gastroenterology 2013;144:912917.e1.

15. Tortora R, Capone P, De Stefano G, et al. Metabolic syndrome in patients with coeliac disease on a gluten-free diet. Aliment Pharmacol Ther 2015;41:352-359.

16. Valentini L, Wirth EK, Schweizer U, et al. Circulating adipokines and the protective effects of hyperinsulinemia in inflammatory bowel disease. Nutrition 2009;25:172-181.

17. Bregenzer N, Hartmann A, Strauch U, Schölmerich J, Andus T,
Bollheimer LC. Increased insulin resistance and beta cell activity in patients with Crohn's disease. Inflamm Bowel Dis 2006;12:53-56.

18. Lanzini A, Magni P, Petroni ML, et al. Circulating ghrelin level is increased in coeliac disease as in functional dyspepsia and reverts to normal during gluten-free diet. Aliment Pharmacol Ther 2006;23:907-913.

19. Capristo E, Farnetti S, Mingrone G, et al. Reduced plasma ghrelin concentration in celiac disease after gluten-free diet treatment. Scand J Gastroenterol 2005;40:430-436.

20. Peracchi M, Conte D, Terrani C, et al. Circulating ghrelin levels in celiac patients. Am J Gastroenterol 2003;98:2474-2478.

21. Selimoglu MA, Altinkaynak S, Ertekin V, Akcay F. Serum ghrelin levels in children with celiac disease. J Clin Gastroenterol 2006;40:191-194.

22. Kempiński R, Demissie M, Jasińska M, Paradowski L. Plasma ghrelin concentration in celiac patients. Gastroenterol Pol 2008;15:375-377.

23. Tomasik PJ, Grzenda-Adamek Z, Sztefko K, Fyderek K. The orexigenic peptides in children with celiac disease. J Appl Res 2009;9:70-75.

24. Karmiris K, Koutroubakis IE, Xidakis C, Polychronaki M, Voudouri T, Kouroumalis EA. Circulating levels of leptin, adiponectin, resistin, and ghrelin in inflammatory bowel disease. Inflamm Bowel Dis 2006;12:100-105.

25. Karmiris K, Koutroubakis IE, Kouroumalis EA. Leptin, adiponectin, resistin, and ghrelin: implications for inflammatory bowel disease. Mol Nutr Food Res 2008;52:855-866.

26. Deboer MD. Use of ghrelin as a treatment for inflammatory bowel disease: mechanistic considerations. Int J Pept 2011;2011:189242.

27. Manavalan JS, Hernandez L, Shah JG, et al. Serum cytokine elevations in celiac disease: association with disease presentation. Hum Immunol 2010;71:50-57.

28. Jarocka-Cyrta E, Kasacka I, Kaczmarski M. The ghrelin-positive cells number is increased in duodenum in children with celiac disease. J Endocrinol Invest 2010;33:165-170.

29. Russo F, Chimienti G, Clemente C, et al. Adipokine profile in celiac patients: differences in comparison with patients suffering from diarrhea-predominant IBS and healthy subjects. Scand J Gastroenterol 2013;48:1377-1385.

30. Shetty S, Kusminski CM, Scherer PE. Adiponectin in health and disease: evaluation of adiponectin-targeted drug development strategies. Trends Pharmacol Sci 2009;30:234-239.

31. Batra A, Zeitz M, Siegmund B. Adipokine signaling in inflammatory bowel disease. Inflamm Bowel Dis 2009;15:1897-1905.

32. Weigert J, Obermeier F, Neumeier M, et al. Circulating levels of chemerin and adiponectin are higher in ulcerative colitis and chemerin is elevated in Crohn's disease. Inflamm Bowel Dis 2010;16:630-637.

33. Paul G, Schäffler A, Neumeier M, et al. Profiling adipocytokine secretion from creeping fat in Crohn's disease. Inflamm Bowel Dis 2006;12:471-477.

34. Herfarth HH, Martin CF, Sandler RS, Kappelman MD, Long MD. 
Prevalence of a gluten-free diet and improvement of clinical symptoms in patients with inflammatory bowel diseases. Inflamm Bowel Dis 2014;20:1194-1197.

35. Waluga M, Hartleb M, Boryczka G, Kukla M, Zwirska-Korczala K. Serum adipokines in inflammatory bowel disease. World J Gastroenterol 2014;20:6912-6917.

36. Bolignano D, Della Torre A, Lacquaniti A, Costantino G, Fries W, Buemi M. Neutrophil gelatinase-associated lipocalin levels in patients with Crohn's disease undergoing treatment with infliximab. J Investig Med 2010;58:569-571.

37. Chan JL, Blüher S, Yiannakouris N, Suchard MA, Kratzsch J, Mantzoros CS. Regulation of circulating soluble leptin receptor levels by gender, adiposity, sex steroids, and leptin: observational and interventional studies in humans. Diabetes 2002;51:2105-2112.

38. Kratzsch J, Lammert A, Bottner A, et al. Circulating soluble leptin receptor and free leptin index during childhood, puberty, and adolescence. J Clin Endocrinol Metab 2002;87:4587-4594.

39. Ertekin V, Orbak Z, Selimoglu MA, Yildiz L. Serum leptin levels in childhood celiac disease. J Clin Gastroenterol 2006;40:906-909.

40. Maggio MC, Corsello G, Iacono G, et al. Gluten-free diet impact on leptin levels in asymptomatic coeliac adolescents: one year of follow-up. Horm Res 2007;67:100-104.
41. Aurangzeb B, Leach ST, Lemberg DA, Day AS. Assessment of nutritional status and serum leptin in children with inflammatory bowel disease. J Pediatr Gastroenterol Nutr 2011;52:536-541.

42. Jönsson T, Memon AA, Sundquist K, et al. Digested wheat gluten inhibits binding between leptin and its receptor. BMC Biochem 2015;16:3.

43. Ockenga J, Tietge UJ, Böker KH, Manns MP, Brabant G, Bahr MJ. Distinct roles of free leptin, bound leptin and soluble leptin receptor during the metabolic-inflammatory response in patients with liver cirrhosis. Aliment Pharmacol Ther 2007;25:1301-1309.

44. Singer E, Markó L, Paragas N, et al. Neutrophil gelatinase-associated lipocalin: pathophysiology and clinical applications. Acta Physiol (Oxf) 2013;207:663-672.

45. Janas RM, Ochocińska A, Śnitko R, et al. Neutrophil gelatinaseassociated lipocalin in blood in children with inflammatory bowel disease. J Gastroenterol Hepatol 2014;29:1883-1889.

46. Oikonomou KA, Kapsoritakis AN, Theodoridou C, et al. Neutrophil gelatinase-associated lipocalin (NGAL) in inflammatory bowel disease: association with pathophysiology of inflammation, established markers, and disease activity. J Gastroenterol 2012;47:519530 